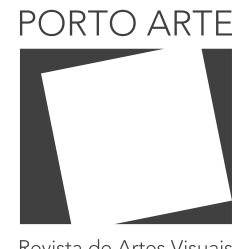

Revista de Artes Visuais

v. 25 ก. 43

Jan/jun 2020 e-ISSN: 2179-8001

\section{Em quarentena: apontamentos sobre educação em museus em tempos de pandemia}

In quarentine: notes on museum education in pandemic times

\section{Camila Schenkel}

ORCID: 0000-0002-5912-6308

Universidade Federal do Rio Grande do Sul, Brasil

\section{Resumo}

O presente artigo reflete sobre os desafios impostos à área de educação em museus durante a pandemia de Covid-19 a partir de três eixos: uma análise de estratégias adotadas por grandes instituições culturais durante o isolamento; a fragilidade das equipes educativas dentro dessas instituições; e as dificuldades de transpor os fundamentos da mediação para o ambiente digital. Recorrendo a pesquisas de Carmen Mörsch sobre mediação e reflexões recentes de Jacques Rancière e Franco Berardi, entre outras referências, destaca-se a importância do conhecimento prático acumulado pelas equipes educativas para desenvolver formas menos excludentes e hierarquizadas de relações com obras e públicos.

Palavras-chave

Museus. Mediação cultural. Atividades online. Públicos. Covid-19.

\begin{abstract}
This article considers de challenges faced by museum education during the Covid-19 pandemics from three points: an analysis of the strategies adopted by mainstream cultural institutions during quarantine; the fragile position of educating teams inside these institutions and the obstacles to transpose the characteristics of mediation to digital platforms. Based on Carmen Mörsch's research on cultural mediation and recent writings of Jacques Rancière and Franco Berardi, among other references, the practical knowledge acquired by education teams is pointed out as a valuable resource in order to develop less excluding and hierarchical relations with works and publics.
\end{abstract}

Keywords

Museums. Cultural mediation. Online activities. Publics. Covid-19. 


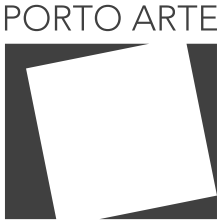

Revista de Artes Visuais

v. 25 n. 43 Jan/jun 2020 e-ISSN: 2179-8001

Figura 1: Convite para visita virtual na página de abertura do site do Metropolitan Museum de Nova York. Fonte: <https: //www metmuseum.org/>. Acesso em 20 maio 2020

\section{Tudo deve mudar para que fique como está}

Os primeiros sinais do impacto da pandemia do novo coronavírus no campo globalizado da arte não demoraram a aparecer. Cerca de um mês depois da Europa identificar os primeiros casos da doença, março de 2020 foi marcado por uma série de fechamentos de museus icônicos, a começar pelo Louvre, logo no primeiro dia. Em meados de maio, relatórios publicados pela UNESCO (2020) e pelo ICOM (2020) apontavam que entre $90 \%$ e $95 \%$ dos museus do mundo se encontravam fechados devido à emergência de saúde. Ambos estudos destacam como consequências diretas desse fechamento o encerramento de contratos com trabalhadores temporários e freelancers, assim como o aumento das atividades digitais dessas instituições.

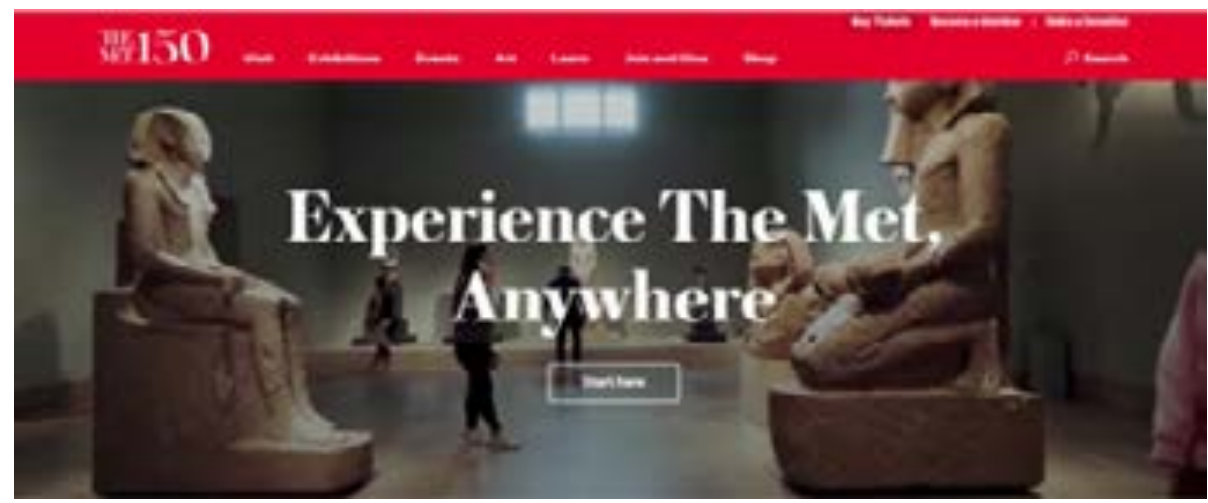

Saem de cena os vernissages, mas entra em ação uma intensa produção de conteúdo para alimentar sites e redes a fim de manter a visibilidade de espaços e de carreiras. É possível participar de encontros online com artistas, curadores e galeristas de toda parte do mundo, acessar espaços distantes por meio de tours virtuais (Fig. 01) e acompanhar exposições criadas especialmente para a internet. Enquanto isso, em nossas caixas de e-mail ou feeds de redes sociais, recebemos indicações de obras, textos e entrevistas, atividades artísticas para fazer com crianças e até mesmo receitas e seleções musicais montadas por artistas ${ }^{1}$. Podemos ler cartas e relatos escritos durante o período de isolamento2; visitar bienais e grandes feiras internacionais que migraram para o ambiente virtual, como a $12^{\mathrm{a}}$ Bienal do Mercosul e a Art Basel; assistir a premières de videoarte; apoiar projetos que buscam alternativas para a produção e a venda de obras de arte

\footnotetext{
1- Como em The Museum from Home, newsletter enviada quinzenalmente para assinantes pelo Museu de Arte Moderna de Nova York.

2- Exemplos desse tipo de iniciativa são os projetos "Notes from Quar, organizado pela plataforma Rhizome com longa atuação na área de arte digital, ou "Letters against Separation", organizado por Hito Steyerl para o e-flux, livremente inspirado em "Decameron", de Bocaccio, com colaborações de artistas e escritores de diferentes continentes.
} 


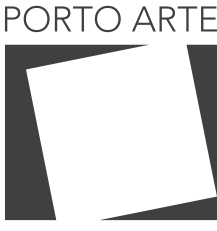

Revista de Artes Visuais

$\vee 25 n .43$

Jan/jun 2020 e-ISSN: 2179-8001

durante a pandemia ${ }^{3}$; realizar em casa instruções criadas por nossos artistas favoritos ${ }^{4}$ ou ainda participar de happy hours com um curador que harmoniza obras da coleção que representa com receitas de coquetéis ${ }^{5}$. Se antes a oferta cultural era filtrada por nossa localização geográfica, a sensação é de que, agora, mesmo com todas as instituições fechadas, tudo está ao nosso alcance, e que é preciso estar sempre alerta e correr contra o tempo para acompanhar as últimas novidades.

Em meio a essa enxurrada de eventos e informações sobre arte, fica evidente, por um lado, a ansiedade de instituições em se manterem visíveis e relevantes, a fim de justificar a manutenção, mesmo a portas fechadas, de equipes e patrocínios. Por outro lado, essas instituições parecem estar falando, se não com elas mesmas, para um tipo de espectador ideal que emerge em meio ao contexto da pandemia: alguém privilegiado o suficiente para poder optar pelo isolamento, que se encontra em casa sem grandes preocupações financeiras ou filhos pequenos, com internet banda larga e tempo disponível para passar horas em frente ao computador acompanhando as últimas movimentações do mundo da arte.

As adaptações de uma atuação eminentemente presencial para atividades online são muitas vezes simplistas, como denuncia a artista Giselle Beiguelman, sem um real investimento na profissionalização da presença digital dessas instituições nem o comissionamento de trabalhos pensados especificamente para esse meio. "Atropelados pela pandemia e sem conteúdo artístico e cultural criado para a web", museus, galerias e instituições culturais "aderiram aos únicos campos da vida online que conhecem, as redes sociais, e-commerce e saídas de emergência apontadas para o Google Arts \& Culture" (BEIGUELMAN, 2020).

Apesar da potencial ampliação de acesso proporcionada pela Internet, excluem-se públicos que não se encontram nessa situação de conectividade ideal, como idosos sem familiaridade com smartphones e Instagram ou jovens de periferia com pacotes de dados limitados ${ }^{6}$, que também poderiam se beneficiar de ofertas culturais em tempos tão desafiadores. Ser parte de um público significa ser alguém solicitado por determinado tipo de objeto ou discurso, habitar um tipo de mundo social, ser motivado por determinados interesses e dispor de certos meios. Em meio à sobrevida digital encontrada pelo campo artístico durante a pandemia de Covid-19, onde foi parar, por exemplo, um dos públicos mais tradicionais de museus, os grupos de escolas públicas anunciados orgulhosamente em relatórios de responsabilidade social para justificar

\footnotetext{
3- Como "Quarentine", projeto colaborativo criado por Lais Myrrha, Marilá Dardot, Cristiana Tejo e Julia Morelli, no qual obras de 45 artistas brasileiros de diferentes trajetórias são vendidas por um mesmo valor, distribuído igualitariamente aos participantes e com uma cota destinada a um fundo emergencial de apoio a pessoas trans afetadas pela epidemia

4- Em meio à quarentena, o Independent Curators International relançou "Do it (home)", parte do projeto idealizado por Hans-Ulrich Obrist que reúne, desde 1993, instruções elaboradas por artistas que servem como partituras para a criação de trabalhos em diferentes lugares, por diferentes pessoas.

5 - Vídeos lançados no YouTube às sextas-feiras, às $17 \mathrm{~h}$, pela The Frick Collection, protagonizados por Xavier F. Salomon. Disponível em: <https://www.youtube.com/playlist?list=PLNVeJpU2DHHR_Oy_Zvgn3MgZQQFCFx2eI>. Acesso em: 20 maio 2020.

6- Essa questão chega a ser apontada na pesquisa divulgada pela UNESCO em meados de maio, que destaca que quase metade da população mundial ainda não tem acesso à Internet (UNESCO, 2020). No Brasil a Pesquisa Nacional por Amostra de Domicílios Contínua - Tecnologia da Informação e Comunicação (Pnad Contínua TIC) 2018, divulgada em abril de 2020 pelo IBGE, indicava que uma em cada quatro pessoas no país não tinha acesso à Internet, sendo que 41,6\% das pessoas sem acesso à rede apontavam não saber utilizá-la como o motivo para não acessá-la (TOKARNIA, 2020).
} 


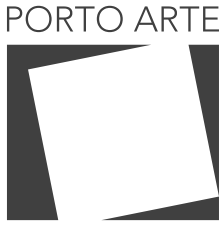

Revista de Artes Visuais

v. 25 ก. 43

Jan/jun 2020 e-ISSN: 2179-8001

investimentos públicos e legitimar o papel dessas instituições nas dinâmicas sociais?

Michael Warner (2020) identifica três acepções diferentes para o conceito de público: um tipo de totalidade social que inclui todos na área em questão (pessoas organizadas em uma nação, estado, comunidade, a humanidade); uma audiência concreta que testemunha a si própria em um espaço visível, que tem um senso de totalidade construído pelo evento ou espaço físico em que estão (como uma peça de teatro ou um jogo de futebol); e uma entidade que se cria em relação a textos e sua circulação, cuja organização independe de instituições do Estado, religiosas ou de leis. Nesse último caso, o público se apresenta como uma audiência imaginária e indefinida, um enquadramento que permite a constituição de um imaginário social. Diante da circularidade dessa última definição, emergem algumas perguntas que parecem de especial importância para esse momento no qual instituições culturais precisam encontrar outros meios de se dirigir à sociedade: é possível falar publicamente sem a existência de um público? Um público pode existir antes de ser endereçado? Um público pode existir fora da retórica em que é imaginado?

Warner, no entanto, alerta:

Um público parece ser auto-organizado pelo discurso, mas, de fato, requer formas preexistentes e canais de circulação. Parece ser aberto a estranhos indeterminados, mas na verdade seleciona participantes por critérios de espaço social compartilhado (mesmo que não necessariamente espaço territorial), habitus, preocupações, referências intergenéricas e formas de circulação inteligíveis (incluindo dialetos ou gêneros de discurso) (WARNER, 2002, p. 106). ?

A existência de um público, portanto, pode ser pensada na articulação entre endereçamento retórico e contexto real de recepção. Ser parte de um público é relacionar-se temporariamente como estranhos por meio da participação. Estaríamos hoje diante de um grande espetáculo virtual sem espectadores, produzido sem preocupação com quem de fato o receberá - como se jogássemos garrafas com mensagens de SOS ao mar, sem ter a mínima ideia de seu destino final?

É preciso lembrar, ainda, que mesmo a atenção desse público ideal da quarentena é disputada com uma oferta sem precedentes de lives de música, filmes e e-books disponibilizados gratuitamente durante a pandemia por editoras, cinematecas e instituições culturais, webinários de livre acesso, além do cardápio de séries e filmes em constante atualização de diferentes serviços de streaming. Também é preciso tempo para acompanharmos as notícias a fim de entender o comportamento do vírus e o alcance da pandemia, nos informarmos sobre novos protocolos de proteção e saber o que está aberto e o que está fechado em nossa cidade — isso sem contar o movimentado noticiário político e policial do Brasil.

7- As citações diretas de obras em língua estrangeira ao longo do artigo são traduções livres realizadas pela autora. 


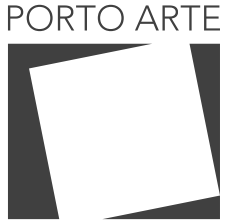

Revista de Artes Visuais

V. $25 \mathrm{n} .43$ Jan/jun 2020 e-ISSN: 2179-8001
Figura 2: Projeção em Santiago do Chile durante os protestos populares iniciados em outubro de 2019. Fonte: <http:// revistadefrente.cl/causalidadde-la-pandemia-cualidad-de-lacatastrofe-por-angel-luis-lara/> Acesso em: 20 maio 2020
A pandemia de Covid-19 catalisa e radicaliza um processo mais amplo de substituição da conjunção física pela conectividade digital (BERARDI, 2020a) e de aceleração dos ritmos de trabalho, de consumo e de trocas informacionais.

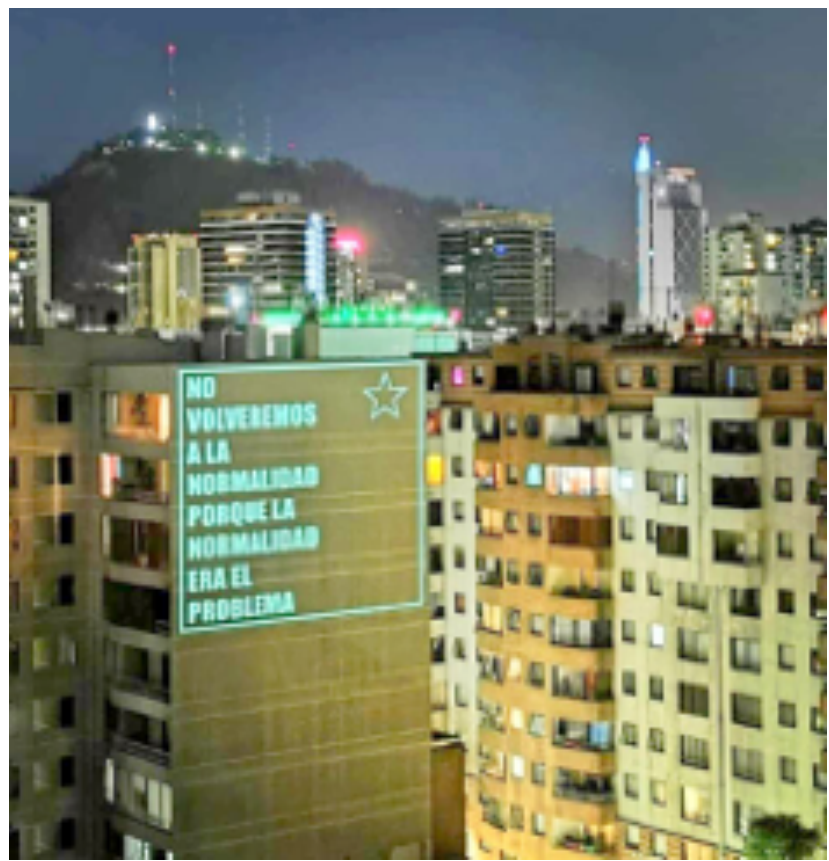

A Web 2.0 possibilitou uma condição de sobrevoo constante: o sujeito não pode experimentar a totalidade dos campos de informação e das trocas, mas faz rasantes sobre eles de tal maneira que, quanto mais perto chega, mais esses campos se expandem e escapam. A aceleração do ciclo informacional concretizada pela banda larga produziu um efeito de perseguição constante: o usuário é apenas um espectador de um fluxo cada vez mais rápido e, por isto, tem sempre a sensação de estar atrasado, de estar fadado a busca sem-fim de uma lufada fugidia de informação (BERARDI, 2020a, p. 177).

A "inércia produtivista" (MOURÃO, 2020) que leva museus e instituições culturais, mesmo em uma situação de completa excepcionalidade, a quererem manter altos níveis de produtividade e rendimento não acomete apenas o campo da arte. Quantas coisas fazemos, recebemos, lemos e ouvimos, isolados em casa, para preencher rapidamente o vazio que se abre em nossos cotidianos diante de uma situação que nunca imaginamos viver? "A catástrofe é rapidamente transformada em rotina", alerta a antropóloga Alana de Morais. "Vamos nos adaptando a qualquer pequena fresta de luz e de repente o comando neurótico de não deixar nos contaminar de mundo adquire inigualável exu- 


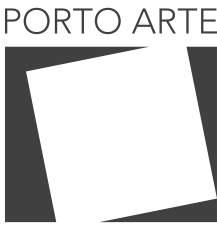

Revista de Artes Visuais

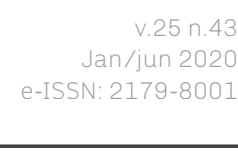

Figura 3: Tussen kunst en quarantaine, Em casa: finalmente Guernica!, postagem de 18 abr. 2020. Fonte <https://www.instagram

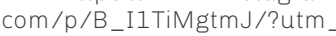
source $=i g \_$embed $>$. Acesso em 20 maio 2020 berância" (MORAIS, 2020, s.p.). Ao repetirmos tantas vezes que a vida continua a mesma, normalizamos um estado de medo que nos faz enxergar o outro como potencial ameaça. Normalizamos a vigilância do Estado para uns - os que podem ficar em casa) -, e o abandono para outros - aqueles que não têm casa, aqueles que precisam sair para as ruas para garantir sua subsistência (Fig. 02).
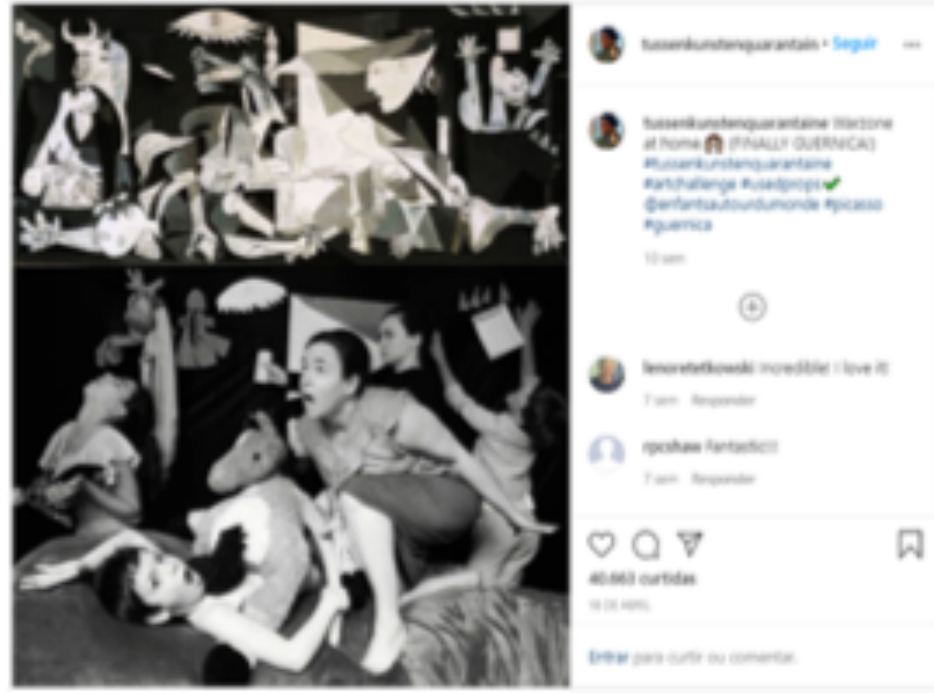

\section{Saem os mediadores, entram as mídias sociais?}

Nessa adaptação abrupta a uma atuação integralmente digital, o trabalho da mediação cultural parece mais importante do que nunca. Com bastante frequência, no entanto, as estratégias online adotadas por museus, galerias e centros culturais são moldadas sobretudo pela visão de curadores, diretores ou mesmo gerentes de marketing e relações públicas dessas instituições, com suas abordagens específicas tanto de seus públicos quanto do próprio fenômeno artístico. Nesse sentido, são exemplares os desafios que correm as redes convocando para que as pessoas recriem, com os materiais que possuem em casa, obras canônicas - uma versão digital do velho exercício escolar de releitura de trabalhos de arte. Um desses sucessos de público é o Getty Museum Challange, do J. Paul Getty Museum, que no final de março convidou os usuários de suas redes sociais a recriarem uma obra de arte com os objetos e pessoas de sua casa. Antes mesmo dele ser lançado, no entanto, a página de Instagram holandesa Tussen Kunst en Quarantaine ("entre arte e quarentena") já alcançava grande popularidade. Criada especialmente para esse fim, ela chamava a todos que estavam em casa precisando de alívio a fazerem produções artísticas caseiras com os materiais que estivessem a seu alcance. Lançada em 14 de março, no final de junho a página contava com 683 publicações e 281 mil seguidores. 


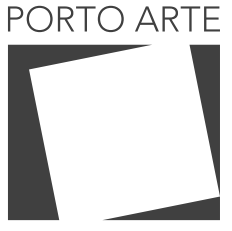

Revista de Artes Visuais

v. 25 n. 43 Jan/jun 2020 e-ISSN: 2179-8001

Figura 4:Antoní Muntadas, "Atenção", 2002, Serigrafia sobre papel, $48,5 \times 85,5 \mathrm{~cm}$ Fonte: <https://www artsy.net/artwork/antonimuntadas-atencao>. Acesso em: 20 maio 2020
Alguns resultados são exemplos impressionantes de criatividade e engenho (Fig. 03), mas será que isso é tudo que a arte tem a nos oferecer nas atuais circunstâncias? Em um momento no qual até mesmo grandes multinacionais como Coca-Cola, Honda,

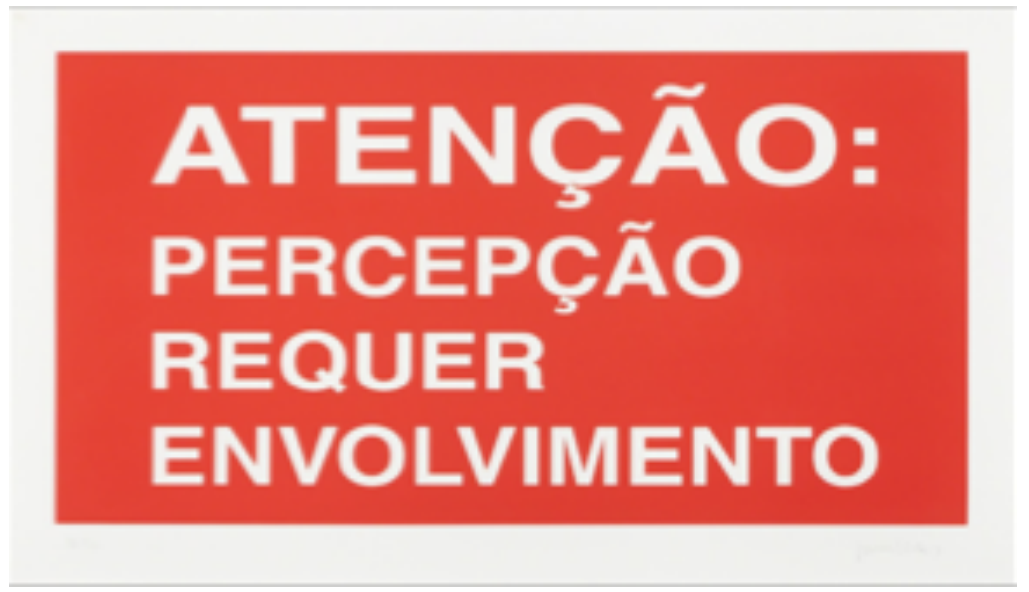

Unilever e Starbucks suspendem seus anúncios no Facebook como forma de pressionar por um maior controle sobre mensagens de ódio nas redes sociais (SANDOVAL, 2020), o humor dessas gambiarras caseiras acaba ganhando um sabor amargo. É preciso nos perguntarmos por que justo o campo da arte, do qual se espera maior consciência crítica, continue a investir nesses meios como a saída mais rápida diante das restrições impostas pelo isolamento social, sem refletir sobre as consequências nefastas da combinação da economia corporativa com a tecnologia digital (MOROZOV, 2018; BERARDI, 2020a).

Para além de soluções midiáticas que garantem a visibilidade dos espaços artísticos durante a suspensão de sua programação regular, coloca-se o desafio de descobrir como o trabalho educativo de museus e instituições culturais pode ter continuidade em tempos de isolamento social, quando um de seus maiores pressupostos, o da presença e convivência com obras e pessoas, encontra-se interditado. Ainda que grande parte das obras de artes visuais tenha uma dimensão física relativamente perene, seu compartilhamento público depende, como a música e o teatro, do encontro em um espaço comum. E mesmo obras que já nascem digitais muitas vezes exigem um ambiente, uma situação e um aparato específico para serem devidamente compartiIhadas ${ }^{8}$. Sua percepção, como nos lembra um trabalho bastante conhecido de Antoní Muntadas, requer envolvimento (Fig. 04).

Uma das atividades mais recorrentes das equipes educativas de museus e instituições culturais são as visitas mediadas, nas quais um profissional acompanha grupos com diferentes características em uma ou mais exposições. Além de ser uma forma de organizar o fluxo de visitantes e acolher pessoas menos familiarizadas com o am-

8- A exceção seria, talvez, trabalhos de net art que exploram justamente sua semelhança ou mesmo indistinção em relação a todo conteúdo não artístico que circula nesse mesmo espaço. 


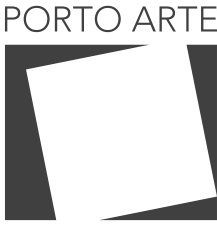

Revista de Artes Visuais

$\vee 25 n .43$

Jan/jun 2020 e-ISSN: 2179-8001

biente da arte, essas visitas proporcionam a possibilidade de construir um pensamento sobre arte em conjunto enquanto caminhamos, olhamos e conversamos, e até mesmo de problematizar nosso estranhamento ou distanciamento em relação aos objetos que são vistos: "o objetivo não é preencher lacunas de entendimento com conhecimento especializado, mas entender as lacunas como ponto de partida para o diálogo e para a experiência estética" (MÖRSCH, 2014, p. 18).

Trata-se de um exercício em que conhecidos ou desconhecidos, a partir do contato com produções artísticas, compartilham ideias e experiências, de maneira a estender e aprofundar o contato com a arte. Com décadas de experiência acumulada em educação em museus, Rika Burnham e Elliot Kai Kee são categóricos: "Entre os entendimentos mais importantes das obras de arte estão aqueles aos quais chegamos em diálogo com outros visitantes [...], alcançando compreensões compartilhadas inacessíveis ao espectador individual" (BURNHAM; KAI-KEE, 2011, p. 1). É esse compromisso coletivo que permite a construção do ambiente de engajamento necessário para o envolvimento efetivo com aquilo que é visto e discutido em uma exposição de arte.

Nessa adaptação do trabalho educativo para o ambiente virtual, um primeiro desafio é manter o próprio espírito da palavra mediação, que ressalta a dimensão de negociação que perpassa essa atividade — um jogo diariamente redefinido entre objetos artísticos, instituições, contextos sociais e pessoas. Há um conflito inerente à mediação que diz respeito a quem tem o direito e a oportunidade de possuir, ver, mostrar ou falar sobre arte: um conflito que é quase tão antigo quanto a própria arte.

A mediação cultural serve para estabilizar e legitimar instituições culturais porque lhes fornece audiência e representa seus interesses para o mundo exterior. Ao mesmo tempo, a mediação cultural também se constitui como uma fonte permanente de perturbação: pelo simples fato de existir, acaba lembrando as pessoas de uma promessa até hoje não realizada - que a arte seja um bem público (MÖRSCH, 2014, p. 36).

A mediação afirma e replica o discurso institucional sobre a arte, mas também o desconstrói e transforma (MÖRSCH, 2016), passando muitas vezes despercebida pelos radares de gestores e patrocinadores, ou sendo conscientemente acolhida, em nome do valor simbólico que a atividade confere a museus e centros culturais. No ambiente de exposição e vigilância da Internet, é possível replicar o espaço de liberdade que a mediação encontra nas brechas do dia a dia das instituições culturais, quando diretores, curadores e artistas se retiram das salas expositivas, deixando a área livre para as equipes que atendem diretamente os visitantes? Há espaço, em sites e redes sociais de museus, institutos culturais e bienais, para discursos que divirjam das narrativas institucionais? 


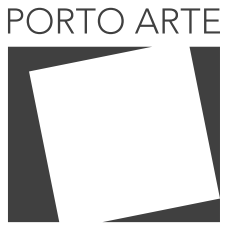

Revista de Artes Visuais v. 25 ก. 43 Jan/jun 2020 e-ISSN: 2179-8001
A concepção de educação que pautou a expansão dos programas educativos a partir do final dos anos 1990 é calcada, sobretudo, em um deslocamento da ideia de instrução para a ideia de experiência, e de um foco nos objetos ou obras de arte para o visitante e para a comunidade na qual a instituição está inserida. Para Jorge Larrosa Bondía,

[...] A experiência, a possibilidade de que algo nos aconteça ou nos toque, requer um gesto de interrupção, um gesto que é quase impossível nos tempos que correm: requer parar para pensar, parar para olhar, parar para escutar, pensar mais devagar, olhar mais devagar, e escutar mais devagar; parar para sentir, sentir mais devagar, demorar-se nos detalhes, suspender a opinião, suspender o juízo, suspender a vontade, suspender o automatismo da ação, cultivar a atenção e a delicadeza, abrir os olhos e os ouvidos, falar sobre o que nos acontece, aprender a lentidão, escutar aos outros, cultivar a arte do encontro, calar muito, ter paciência e dar-se tempo e espaço (BONDÍA, 2002, pp. 21-24).

Com a aceleração do cotidiano e o desenvolvimento da sociedade de informação, no entanto, os desafios para sermos de fato atravessados e mobilizados pela arte, seja a partir do contato presencial com uma exposição ou por aproximações mediadas por aparelhos e tecnologias digitais, parecem aumentar a cada dia. Como estabelecer vínculos no ambiente altamente dispersivo que é a Internet? Como dar densidade e espessura a suas imagens comprimidas e migrantes, sujeitas a falhas técnicas e a descontextualizações? E como manter o envolvimento necessário para a experiência estética quando estamos sós, diante de telas de computadores ou celulares?

0 ambiente de hipercomunicação das redes digitais acaba sendo com maior frequência mais o palco de monólogos do que de diálogos, no qual a maior parte dos usuários atua como consumidora de uma minoria produtora de conteúdo (SENNETT, 2013). No caso específico das inúmeras atividades culturais lançadas nas redes nos últimos meses, é preciso analisar a quem se dirigem essas propostas e o quanto essas instituições de fato permitem e estão atentas à participação de seus públicos.

\section{Um vírus que evidencia a nossa precariedade}

As primeiras notícias internacionais sobre as consequências do fechamento de museus e instituições culturais nos Estados Unidos são sintomáticas da especial fragilidade da área educativa em meio à crise instaurada pela disseminação da COVID-19. Ainda em meados de março, a Fundação Serralves, do Porto, dispensou toda sua equipe de educadores contratados, totalizando 23 demissões. No início de abril, os 85 educadores freelancers do Museu de Arte Moderna de Nova York receberam um e-mail comunicando a suspensão de suas contratações, com a justificativa de que poderia levar meses e até mesmo anos até que o museu retornasse aos níveis de orçamento 


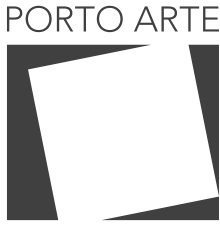

Revista de Artes Visuais

v. 25 ก. 43

Jan/jun 2020 e-ISSN: 2179-8001

e atividades que exigissem serviços educativos. No mesmo período, também em Nova York, o New Museum se desfazia de quase um terço de sua equipe, entre contratos de meio turno ou de tempo integral, e o Whitney Museum realizava o desligamento de 75 funcionários. Uma petição lançada no mesmo mês pelo coletivo anônimo NYC Workers, além de pedir para que as instituições fizessem tudo a seu alcance para não demitir nenhum colaborador, também chamava a atenção para as disparidades salariais entre os cargos diretivos e os trabalhadores da linha de frente, usualmente os primeiros a serem demitidos, colocando em risco tanto a memória dessas instituições quanto seus recentes avanços em matéria de diversidade cultural (BISHARA, 2020).

Ainda no mesmo mês, quando os impactos da pandemia no setor cultural começavam a ser mensurados, uma carta aberta endossada por artistas, curadores, educadores, críticos e historiadores de diferentes países, que hoje conta com mais de 1500 assinaturas, expressava grave preocupação com a onda de demissões que atingia os setores educativos de museus globais como o MoMA, o LA MOCA e a Fundação Serralves. A carta, que ao final implorava que museus aproveitassem essa crise para, junto com seus trabalhadores e seus públicos, reimaginar o papel da cultura durante e depois da pandemia, argumentava que:

Longe de serem dispensáveis, tais trabalhadores - empregados para realizar visitas, projetar e desenvolver programas para escolas e comunidades de todas as idades - estão no centro da atuação de museus e galerias. Sendo aqueles com maior contato com as comunidades de fora do museu, educadores impulsionam a crítica e a inovação. Seu trabalho é regularmente usado para atrair doadores e apoiadores para muitas instituições. Que eles sejam os primeiros da fila de demissões é desconcertante. ${ }^{9}$

Cabe ressaltar, no entanto, que a precariedade da área não se limita ao cenário de emergência de saúde mundial. Educativos de museus operam de forma cada vez mais precária, sem vínculo empregatício e com remunerações mais baixas que as de outros profissionais, ou até mesmo de modo voluntário, o que transforma este trabalho, cada vez mais, em um estado transitório, dificultando os avanços na área.

O quadro é especialmente dramático quando focamos no Brasil, com seu histórico recente de encolhimento de investimentos públicos e privados no setor cultural e ataques políticos cada vez mais frequentes à classe artística e à educação. Com as consequências econômicas da pandemia, que afetarão toda a cadeia produtiva da cultura, da criação ao consumo, a pesquisadora Ana Leticia Fialho (2020) aponta o eminente risco de colapso

\footnotetext{
9- A carta está disponível para consulta e assinatura online em: <https://docs.google.com/forms/d/e/ 1FAIpQLSffndW5BKqpgasNmIkxUTZr58SI7HPM2LAcAiCEy6XgJ7R-RQ/viewform?fbclid=IWAROFvKensuvnOGzyVTKXHn-IQdhXI9cy3CSmnDVsJA6UGZugOL_LuZNpfSs>. Acesso em 20 maio 2020.
} 


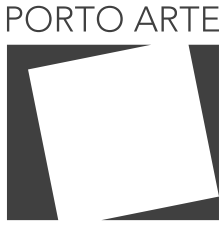

Revista de Artes Visuais

v. 25 n. 43 Jan/jun 2020 e-ISSN: 2179-8001

Figura 5: Dan Perjovschi, "Sponsor", 2005. Fonte: <https://www.on-curating.org/ issue-24-reader/sponsor-2005. html\#.XwhfIChKjIU>. Acesso em: 20 maio 2020 do setor, caso o Estado não adote medidas econômicas e regulatórias vigorosas ${ }^{10}$. Pesquisas da revista seLecT e do Observatório de Economia Criativa da Bahia (OBEC) com dados coletados em abril apontavam que, de um universo de cerca de 1000 participantes, "mais de $50 \%$ dos profissionais mapeados têm renda inferior a 3 salários mínimos, alto grau de informalidade e dependem majoritariamente das atividades exercidas no setor cultural para sobreviver" (FIALHO, 2020). Dados da seLecT revelavam que $11,5 \%$ dos entrevistados já haviam sido demitidos, enquanto 5,8\% tiveram o trabalho suspenso com remuneração total e 5,2\% com remuneração parcial (SELECT, 2020). Profissionais com atuação na área educativa representavam $13,7 \%$ dos respondentes. Já as informações coletadas pelo OBEC apontavam que $15 \%$ das instituições havia realizado demissões (FIALHO, 2020).

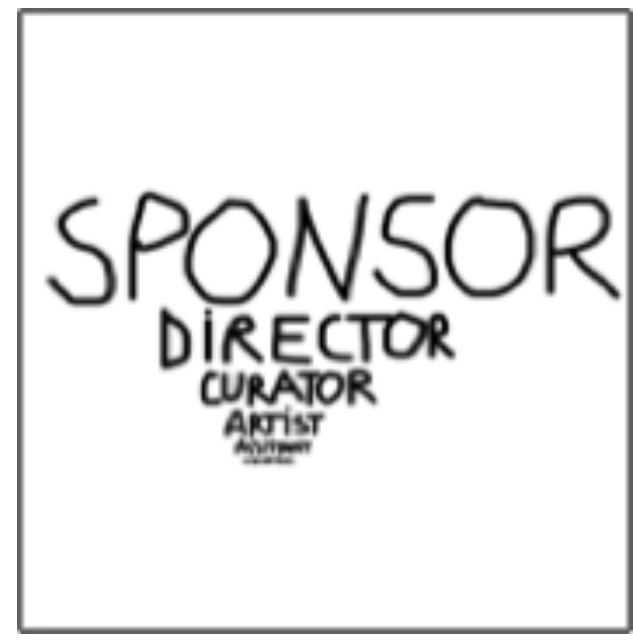

Em 19 de maio de 2020, após o governo de São Paulo decretar um corte de $14 \%$ no repasse às organizações sociais que gerenciam a cultura no estado, trabalhadores demitidos do Museu Afro Brasil publicaram uma carta aberta em que denunciavam a demissão de 23 dos 80 funcionários da instituição - entre eles todos os seus educadores - sem proposta de redução de salário, carga horária ou suspensão temporária de contrato (MICHEL, 2020). No mesmo período, se contabilizavam 60 demissões na área cultural do SESI São Paulo, outras 60 em centros culturais da cidade do Rio de Janeiro, como o Centro de Arte Hélio Oiticica, o Centro Cultural Sérgio Porto e o Museu Histórico da Cidade, enquanto a Rede de Educadores de Museus apontava que ao menos 35 instituições no país já haviam demitido educadores (FIORATTI, PAMPLONA, 2020), entre elas o Centro Cultural Banco do Brasil, o Museu de Arte Sacra de São Paulo, e o Museu de Arte Moderna do Rio. Com o agravamento e prolongamento da crise, o cenário se torna ainda mais drástico.

10- A maior ação de âmbito nacional, nesse sentido, é a Lei 14.017/20 - Lei de Emergência Cultural Aldir Blanc, com origem no Projeto de Lei 1075/20 da deputada Benedita da Silva (PT-RJ), que prevê auxílio de R\$ 600 a profissionais do setor e de R\$ 3 mil a R\$ 10 mil a espaços culturais. O projeto foi aprovado no Congresso Nacional em 26 de maio de 2020 e uma semana depois no Senado, mas só foi sancionado pelo Presidente da República, Jair Bolsonaro, em 29 de junho, um dia antes de expirar, porém com veto ao prazo de até 15 dias para a realização dos repasses (PINTO, 2020). 


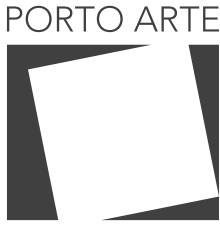

Revista de Artes Visuais

v. 25 ก. 43

Jan/jun 2020 e-ISSN: 2179-8001

Não é nada surpreendente que sejam justamente os trabalhadores da linha de frente, como mediadores e equipes terceirizadas de limpeza e segurança, os mais suscetíveis em meio à crise instaurada pelo novo coronavírus, enquanto posições de maior destaque e salário permanecem resguardadas. Mas é preciso ressaltar que, justamente no momento em que as instituições culturais precisam construir novas formas de se relacionar com seus públicos, elas estão dispensando justamente aqueles que melhor os conhecem. Evidencia-se, nesse contexto de pandemia, aquilo que os profissionais da área já percebem há tempo: que os museus enxergam os educadores como "meros executores, mediadores de público que auxiliam a instituição a atingir metas e contrapartidas sociais de patrocinadores, ao contrário de potenciais interlocutores internos" (QUINTELLO, 2020).

Os saberes produzidos no cotidiano das atividades educativas de instituições culturais ainda permanecem, em grande medida, invisíveis e, com a onda de demissões que vem na esteira na pandemia, serão definitivamente perdidos. Apesar de termos hoje uma quantidade considerável de estudos sobre educação em museus sendo publicados, poucos jogam luz sobre as experiências do mediador, os encontros e desencontros que se produzem no dia a dia das exposições e dos ateliês. Desvalorizado dentro da hierarquia do campo da arte (Fig. 05), esse conhecimento que vem da prática só consegue - quando consegue - chegar às discussões sobre a programação e às políticas das instituições depois de passar por muitos filtros. Em pleno século XXI, os museus ainda permanecem bastante impermeáveis em relação ao que acontece dentro de suas próprias paredes.

\section{Um apagar de luzes ou um curto-circuito}

As primeiras análises das consequências sociais e culturais da pandemia que em poucos meses levou o mundo a uma inédita quarentena de proporções globais se encaminham para dois rumos diferentes. Há, por um lado, os que a veem como uma grande aceleradora de projetos em andamento de controle e vigilância social, consagrando tecnologias como aplicativos que monitoram a movimentação de seus usuários e alertam quando houver contato próximo com alguém infectado, ou o uso de sensores térmicos em locais públicos, como o sistema de câmeras já em teste na Estação da Sé do metrô de São Paulo (AMBROSIO, RIBEIRO, 2020). No outro polo, filósofos como Slavoj Žižek (2020) e Franco Bifo Berardi (2020b) percebem no caos que a Covid-19 trouxe para o sistema capitalista global uma brecha inesperada para a construção de uma sociedade alternativa:

Poderíamos sair dessa situação imaginando uma possibilidade que até ontem parecia impensável: redistribuição de renda, redução do tempo de trabalho. Igualdade, frugalidade, abandono do paradigma de crescimento, investimento de energias sociais em pesquisa, em educação, em saúde. Não podemos saber como sairemos da pande- 


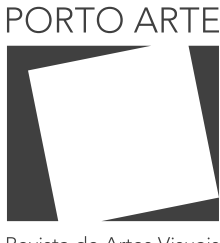

v. 25 n. 43 Jan/jun 2020 e-ISSN: 2179-8001 mia cujas condições foram criadas pelo neoliberalismo, pelos cortes na saúde pública, pela hiperexploração frenética. Podemos sair dela definitivamente sós, agressivos, competitivos. Mas, pelo contrário, podemos sair dela com um grande desejo de abraçar: solidariedade social, contato, igualdade. (BERARDI, 2020b, p. 54)

O campo da arte também começa a se perguntar que mundo artístico gostaríamos de reencontrar quando museus, centros de arte, bienais, feiras e galerias puderem reabrir suas portas. Essa parada forçada e prolongada poderia servir para que as instituições artísticas revissem tanto suas narrativas quanto sua estrutura. Que nossas instituições, em vez de precisar inventar a cada semana novos eventos e notícias, comecem a olhar para o que construíram até aqui, e para o que precisa ser revisto e transformado, não apenas por conta da emergência de saúde e da crise econômica que se impõem, mas pela necessidade de desenvolver uma concepção de arte menos excludente, assim como um sistema de trabalho mais justo. Em relação à área de arte-educação, especificamente, essa suspensão poderia dar a educadores e mediadores, finalmente, um tempo mais prolongado de reflexão sobre suas práticas, que dificilmente conseguiriam se estivessem trabalhando normalmente - tempo para compreender o que está acontecendo e os desafios que virão, tempo para desenvolver novas perspectivas de atuação e imaginar outras formas de ação na esfera pública.

"Mas quem fará o necessário para mudar tudo, quando a marcha econômica for retomada depois do curto-circuito do vírus?" - pergunta Jacques Rancière (2020, p. 7), ao olhar com ceticismo tanto para essas leituras da vida pós-pandemia que reconhecem o triunfo do biopoder e da ditadura do digital quanto para as profecias de colapso do capitalismo exploratório. "Um futuro só se constrói na dinâmica de um presente" (RANCIÈRE, 2020, p. 7), alerta. É preciso nos comprometermos, desde agora, em desenvolver novas formas de fazer, compartilhar e pensar a arte, reposicionando seu papel na sociedade. E pensar com outros, pensar com quem não costuma ser ouvido por essas instituições, é crucial para que o ponto de chegada não sejam soluções que já não dão conta das urgências atuais.

\section{REFERÊNCIAS}

ARTFORUM. "MOMA and New Museum Among NY Institutions Cutting Jobs to Curb Deficits". Artforum News, New York, Apr. 03, 2020. Disponível em: <https://www. artforum.com/news/moma-and-new-museum-among-ny-institutions-cuttingjobs-to-curb-deficits-82681>. Acesso em: 10 maio 2020.

AMBROSIO, Alana; RIBEIRO, Tayguara. "Metrô testa câmera para medir a temperatura dos passageiros em SP". Folha de S. Paulo, São Paulo, 2 jul. 2020. Disponível em: $<$ https://agora.folha.uol.com.br/sao-paulo/2020/07/metro-testa-camera-para-medir-a-temperatura-dos-passageiros-em-sp.shtml>. Acesso em: 02 jul. 2020.

BERARDI, Franco "Bifo". Asfixia: capitalismo financeiro e a insurreição da linguagem. 


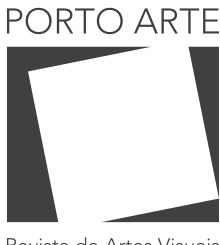

Revista de Artes Visuais $\vee 25 n .43$ Jan/jun 2020 e-ISSN: 2179-8001

São Paulo: Ubu, 2020a.

. "Crónica de la psicodeflación". In: AGAMBEN, Giorgio et al. Sopa de Wuhan: pensamiento contemporáneo en tiempos de pandemias. ASPO, 2020b, pp. 35-54. Disponível em: <https://drive.google.com/file/d/1bpWWb7X4CRi-VFyMIeQhtNEsIFneKmqk/view>. Acesso em: 15 maio 2020.

BISHARA, Hakim. "Artists, Scholars, and Museum Workers Petition Museums to Retain Staff During Pandemic". Hyperallergic, New York, 20 abr. 2020. Disponível em: <https://hyperallergic.com/557148/petitions-retain-staff-during-pandemic/>. Acesso em: 10 maio 2020.

BONDÍA, Jorge Larrosa. "A experiência e o saber da experiência". Revista Brasileira de Educação, n. 19, 2002, pp. 21-24.

BEIGUELMAN, Giselle. "Atropelados pela pandemia, museus rastejam na internet". FoIha de S. Paulo, São Paulo, 08 maio 2020. Disponível em: <https://www1.folha. uol.com.br/ilustrada/2020/04/atropelados-pela-pandemia-museus-rastejam-na-idade-da-pedra-da-internet.shtml>. Acesso em: 10 maio 2020.

BURHAM, Rika; KAI-KEE, Elliott. Teaching in the Art Museum: Interpretation as Experience. Los Angeles: Getty Publications, 2011.

FIALHO, Ana Letícia. "O iminente colapso do setor cultural". seLecT, São Paulo, maio 2020. Disponível em: <http://www.canalcontemporaneo.art.br/brasa/archives/009976.html>. Acesso em: 16 jun. 2020.

FIORATTI, Gustavo; PAMPLONA, Nicola. "Semana termina com centenas de demissões em redes de museus e teatro". Folha de S. Paulo, São Paulo, 23 maio 2020. Disponível em: <https://www1.folha.uol.com.br/ilustrada/2020/05/semana-termina-com-centenas-de-demissoes-em-redes-de-museus-e-teatro.shtml>. Acesso em: 02 jun. 2020.

ICOM. "Report: Museums, museum professionals and COVID-19". Paris: International Council of Museums, 26 maio 2020. Disponível em: <https://icom.museum/ wp-content/uploads/2020/05/Report-Museums-and-COVID-19.pdf>. Acesso em: 30 maio 2020.

MICHEL, Fabio. "Em carta aberta, demitidos do Museu Afro Brasil denunciam desmonte e pedem apoio". Rede Brasil Atual, São Paulo, 24 maio 2020. Disponível em: <https://www.redebrasilatual.com.br/cultura/2020/05/em-carta-aberta-demitidos-do-museu-afro-brasil-denunciam-desmonte-e-pedem-apoio/>. Acesso em: 02 jun. 2020.

MORAIS, Alana. "Atravessar como Medusas contra as coordenadas dos heróis". Textos n-1 edições, São Paulo, n. 32, 2020. Disponível em: <https://n-1edicoes. org/032>. Acesso em: 20 maio 2020.

MOROZOV, Evgeny. Big Tech: a ascensão dos dados e a morte da política. São Paulo: Ubu, 2018.

MÖRSH, Carmen. "Numa encruzilhada de quatro discursos. Mediação e educação na documenta 12: entre Afirmação, Reprodução, Desconstrução e Transformação". Periódico Permanente, n. 6, São Paulo, mar. 2016. Disponível em: <http://www. forumpermanente.org/revista/numero-6-1/conteudo/numa-encruzilhada-de- 


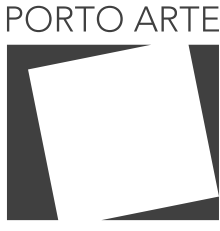

Revista de Artes Visuais $\vee 25 n .43$ Jan/jun 2020 e-ISSN: 2179-8001

-quatro-discursos-1-mediacao-e-educacao-na-documenta-12-entre-afirmacao-reproducao-desconstrucao-e-transformacao-2>. Acesso em: 07 maio 2020.

MÖRSCH, Carmen et al. Time for Cultural Mediation. Zurich: Institute for Art Education of Zurich University of the Arts (ZHdK), 2014.

MOURÃO, Patrícia. "Inércia produtivista: sistema da arte vive síndrome maníaca de produção de visibilidade em tempos de Covid-19". seLecT, São Paulo, abr. 2020. Disponível em: <https://www.select.art.br/inercia-produtivista/>. Acesso em 02 maio 2020.

PINTO, Vera. "Veto à Lei Aldir Blanc causa apreensão". Correio do Povo, Porto Alegre, 02 jul. 2020. Disponível em: <https://www.correiodopovo.com.br/arteagenda/veto-\%C3\%A0-lei-aldir-blanc-causa-apreens\%C3\%A3o-1.444142>. Acesso em: 03 jul. 2020.

QUINTELLE, Pollyana. "Sem margem de negociação. Demitir educadores durante a quarentena expõe a hipocrisia das instituições culturais". seLecT, 16 abr. 2020. Disponível em: <https://www.select.art.br/sem-margem-de-negociacao/>. Acesso em: 03 maio 2020.

SANDOVAL, Pablo. "Cresce o boicote de grandes anunciantes contra o Facebook apesar da reação de Zuckerberg". El país, 29 jun. 2020. Disponível em: <https://brasil. elpais.com/tecnologia/2020-06-29/cresce-o-boicote-de-grandes-anunciantes-contra-o-facebook-apesar-da-reacao-de-zuckerberg.html>. Acesso em: 29 jun. 2020.

SELECT. "Resultado da pesquisa seLecT: trabalhadores da arte". seLecT, São Paulo, 29 abr. 2020. Disponível em: <https://www.select.art.br/pesquisa-select-trabalhadores-da-arte-2/>. Acesso em: 02 maio 2020.

SENNET, Richard. Together: The Rituals, Pleasures and Politics of Cooperation. Penguin: London, 2013.

TOKARNIA, Mariana. "Um em cada 4 brasileiros não tem acesso à internet, mostra pesquisa". Agência Brasil, 29 abr. 2020. Disponível em: <https://agenciabrasil.ebc. com.br/economia/noticia/2020-04/um-em-cada-quatro-brasileiros-nao-tem-acesso-internet>. Acesso em: 10 jun. 2020.

UNESCO. "Unesco Report: Museums around the World in the Face of COVID-19". Paris: United Nations Educational, Scientific and Cultural Organization (UNESCO), maio 2020. Disponível em: <https://unesdoc.unesco.org/ark:/48223/ pf0000373530>. Acesso em: 30 maio 2020.

ŽIŽEK, Slavoj. "Coronavirus es un golpe al capitalismo al estilo 'Kill Bill' y podría conducir a la reinvención del comunismo". In: AGAMBEN, Giorgio et al. Sopa de Wuhan: pensamiento contemporáneo en tiempos de pandemias. ASPO 2020, pp. 21-28. Disponível em: <https://drive.google.com/file/d/1bpWWb7X4CRi-VFyMIeQhtNEsIFneKmqk/view>. Acesso em: 06 maio 2020. 


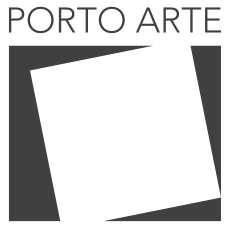

Revista de Artes Visuais

V.25 n. 43

Jan/jun 2020 e-ISSN: 2179-8001

Texto recebido em: 15/06/2020 Texto publicado em: 30/06/2020

\section{Camila Schenkel}

Professora e pesquisadora do Instituto de Artes da Universidade Federal do Rio Grande do Sul, onde ministra aulas nos cursos de graduação em Artes Visuais e em História da Arte e na Especialização em Práticas Curatoriais. Possui doutorado em Artes Visuais no Programa de Pós-Graduação em Artes Visuais da UFRGS, área de concentração História, Teoria e Crítica da Arte (2016), com estágio de doutorado-sanduíche no Departamento de Artes Visuais da Università di Bologna (2015) e pesquisa de pós-doutorado no PPGAV-UFRGS (2017). Foi mediadora da $8^{\text {a }}$ Bienal do Mercosul (2011) e coordenou o Programa Educativo da Fundação Iberê Camargo de 2012 a 2017. 